\title{
Abnormally High Power Output of Wind Turbine in Cold Weather: A Preliminary Study
}

\author{
Christophe Leclerc and Christian Masson \\ Département de génie mécanique, École de technologie supérieure, Montréal, Québec, Canada
}

According to popular belief, air temperature effects on wind turbine power output are produced solely by air density variations, and power is proportional to air density. However, some cases have been reported, all involving stallcontrolled wind turbines, in which unexpected high power output was observed at very low temperatures.

As a preliminary study, this article intends to quantify the influence of air temperature on the power production of the Tacke TW600 wind turbine installed in Tiverton, Ontario, Canada. Increases in power output due to air temperature variation are stratified by wind velocity, showing that these increases are below the theoretical limits of air density variations during operation in low winds and are comparable to and beyond those theoretical limits at higher wind velocities. At $-9^{\circ} \mathrm{C}$ and $0^{\circ} \mathrm{C}$, narrow bands of power at distinct levels are observed in the stall regime of the turbine; they are typical of many stall phenomena observed on stall-controlled rotors, but these levels have been found to be independent of any parameters recorded.

Keywords multiple stall, overproduction, power output, Reynolds number, temperature, wind turbine

Received 5 April 2001; accepted 12 April 2001.

The authors are grateful to the Institut de Recherche en Électricité du Québec (IREQ) wind energy research group and especially to Réal Reid, who reported to us the abnormal power outputs observed at very low temperatures. The authors are also grateful to Ontario Hydro, specifically Peter Golbeck, for help in obtaining the recordings and for the detailed information about the Tiverton wind turbine. This work was supported by the Ministère des ressources naturelles du Québec through the Programme d'aide au développement des technologies de l'énergie. The support of the Natural Sciences and Engineering Research Council of Canada (NSERC) and of the Fonds pour la formation des Chercheurs et l'Aide à la Recherche du Québec (FCAR) in the form of research grants to C. Masson is gratefully acknowledged.

Address correspondence to Dr. Christian Masson, Département de génie mécanique, École de technologie supérieure, 1100. rue Notre Dame Ouest, Montréal, Québec H3C 1K3, Canada. E-mail: cmasson@mec.etsmtl.ca
In Kuujjuak, Québec, Reid (1998) reported that 5-min averaged power outputs of $89 \mathrm{~kW}$ were recorded on a $65 \mathrm{~kW}$ Bonus wind turbine during cold-weather operation. In Igloolik, Northwest Territories, Lodge (1996) observed 10-min averaged power outputs of $16 \mathrm{~kW}$ and instantaneous power outputs of $20 \mathrm{~kW}$ on two $10 \mathrm{~kW}$ Aerowatt wind turbines at very low temperatures. In Pyhätunturi, Finland, Peltola and colleagues (1996) reported that a $220 \mathrm{~kW}$ rotor produced power output peaks of $360 \mathrm{~kW}$ in very cold weather, leading to excessive loading and failure of the generator. All these events involve stall-controlled wind turbines and are recurrent in the sense that they manifest themselves under identical operating conditions, essentially in very cold weather (below $-20^{\circ} \mathrm{C}$ ) and in high wind velocities, typical of stall operation. As the power levels recorded largely exceed the design levels of the rotors, operation in such conditions can cause severe damage to the mechanical or electrical components of the turbine.

Similar behavior has been observed on the $600 \mathrm{~kW}$ Tacke wind turbine installed near Tiverton, Ontario, Canada. This stallcontrolled, three-bladed rotor was put into service on October 1, 1995, with the same settings as the Tacke rotors installed in Europe. Soon afterwards, second-averaged power peaks of $950 \mathrm{~kW}$ were recorded in $-20^{\circ} \mathrm{C}$ weather, at which time the generator overheated and tripped out. Normal operation of the turbine was then compromised, and on November 24 of the same year, the blade pitch angle was modified by 1 degree, limiting the power peaks to about $800 \mathrm{~kW}$.

It can be demonstrated, using dimensional analysis applied to a rotor immersed in a uniform and inviscid incoming flow, that the rotor power coefficient is independent of temperature and, consequently, rotor torque and power are directly proportional to air density. This is not the case for a turbine immersed in the atmospheric boundary layer, since viscosity and turbulence are strongly influenced by air temperature, together with other parameters of importance to the productivity of a wind turbine.

This study was an analysis of experimental data recorded on the Tiverton Tacke TW600 wind turbine to quantify the effects of temperature on the power performances of a rotor. The influence 
of density, Reynolds number, and wind direction on power performances was also studied. Data recorded by the turbine sensors consisted of 10-min averaged values of wind velocity, electrical power, wind direction, and temperature.

The data on atmospheric pressure and humidity that were used to compute density were provided by Environment Canada and were those measured on the nearby site of Goderich. An original regression method was used to build the power curves of the wind turbine for each integer value of the air temperature between $-40^{\circ} \mathrm{C}$ and $+36^{\circ} \mathrm{C}$. Considering these analytical curves to be the best estimates of the turbine's behavior, the increase of electrical power due to air temperature for a given wind velocity was studied and correlated with air density variations. Correlation between temperature and air density as well as between temperature and Reynolds number was also made. Experimental data recorded at $-9^{\circ} \mathrm{C}$ and $0^{\circ} \mathrm{C}$ exhibited distinct bands of power at various levels in the stall regime of the turbine, commonly referred to as multiple stall events. Finally, conclusions were drawn about the influence of temperature on the power performances of the Tiverton wind turbine, and some hypotheses were proposed to explain these unexpected increases in power.

\section{THE POWER CURVE AS A FUNCTION OF TEMPERATURE}

\section{Description of Experimental Data}

The Tacke TW600 under investigation is a three-bladed, stallcontrolled, $600 \mathrm{~kW}$, horizontal-axis wind turbine. This 43-m diameter rotor is fixed at a hub height of $50 \mathrm{~m}$, and it can operate at two rotational velocities, namely 18 and $27 \mathrm{rpm}$. In starting conditions, the rotor works at a low rotational velocity, shifting up to high rotational velocity when electrical power production exceeds a threshold value. The turbine is located near Tiverton, $3 \mathrm{~km}$ from the shore of Lake Huron. The topography north and east of the wind turbine is rolling farmland; to the south lies the Bruce industrial park, where buildings are $10 \mathrm{~m}$ in height, and to the west there is a steep ravine.

The monitoring of the rotor is achieved by means of continuous recordings of the following parameters: date and time, wind velocity, electrical power output, rotational velocity of the generator shaft, wind direction, outside air temperature, and other parameters related to wind turbine components. Hour-averaged, 10-min-averaged, and second-averaged values of these parameters are continuously stored. The data used in this study were 10-min averages for the period between December 1995 and August 1998. Data recorded during off-grid operation and when ice accretion was observed on blades or sensors were rejected, and two groups of recordings were formed, corresponding to the two rotational modes of the turbine. After this treatment, sets of 12,000 and 10,000 recordings were obtained for the low and high rotational velocities, respectively, using as a classification criteria a maximum deviation of $2.5 \%$ of the shaft's rotational velocity with respect to its nominal values.

\section{Construction of Power Curves}

For a given rotational speed, electrical power was considered by this study to be a function of wind velocity and temperature only, ignoring the effects of turbulence, wind direction, Reynolds number, air density, and other operational parameters. For every integer value of temperature between the minimum $\left(-40^{\circ} \mathrm{C}\right)$ and maximum $\left(36^{\circ} \mathrm{C}\right)$ temperatures recorded, the power performance curves for the two rotational speeds of the Tiverton turbine can be obtained through regression analysis of experimental recordings. Values of temperature measured by the turbine's sensors are stored in integer format, so data recorded at the same temperature were regrouped and one-variable regression analysis was used on the resulting groups, rather than using the less tractable two-variable regression analysis. For this type of analysis, the mathematical models commonly used involve least squares methods, such as polynomial regression or nonlinear regression.

The typical power-performance curve of a modern wind turbine is generally linear at low wind velocities and bell-shaped at moderate wind velocities; an essentially constant level of power output occurs during higher wind velocities. Polynomial regression seems to be inadequate to capture these features of powerperformance curves, especially when few recordings are available. Figure 1 shows the four-order polynomial regression curve obtained from the $-5^{\circ} \mathrm{C}$ recordings at high blade-rotational velocity. At high wind velocities, the data scattering clearly makes the shape of the resulting regression curve unrealistic.

The performances of a wind turbine are often reported in nondimensional form, using the following nondimensional parameters:

$$
C_{P}=\frac{P}{\frac{1}{2} \rho V^{3} \pi R^{2}} \quad \lambda=\frac{\omega R}{V}
$$

where $C_{P}$ is the coefficient of power, $P$ is the electrical power, $V$ is the wind velocity at hub height measured by the turbine anemometer, $\lambda$ is the tip speed ratio, $\omega$ is the rotational velocity, and $R$ is the rotor radius. Physically relevant regression analysis can be obtained from the coefficient of power since its behavior, as a function of the tip-speed ratio, closely follows the shape of a parabola. Regression analysis based on the coefficient of power will be denoted regression on $C_{P}$. Figures 1 and 2 show the power curves obtained when using a four-order regression polynomial on $C_{P}$. Using the definitions of the nondimensional parameters presented in Equation (1), it is possible to demonstrate that this approach is equivalent to a nonlinear regression of the electrical power curve with a function of the form $a V^{2}+b V+c+d / V+e / V^{2}$. The weakness of this approach is clearly observable for high wind velocities (see Figure 2), for which $C_{P}$ and $\lambda$ tend toward 0 , thus influencing drastically the lowest coefficients of the regression polynomial and, consequently, the power curve in the region of high wind velocities.

The approach finally adopted in this work, denoted regression on $C_{P}^{M O D}$, consists of a four-order polynomial regression 


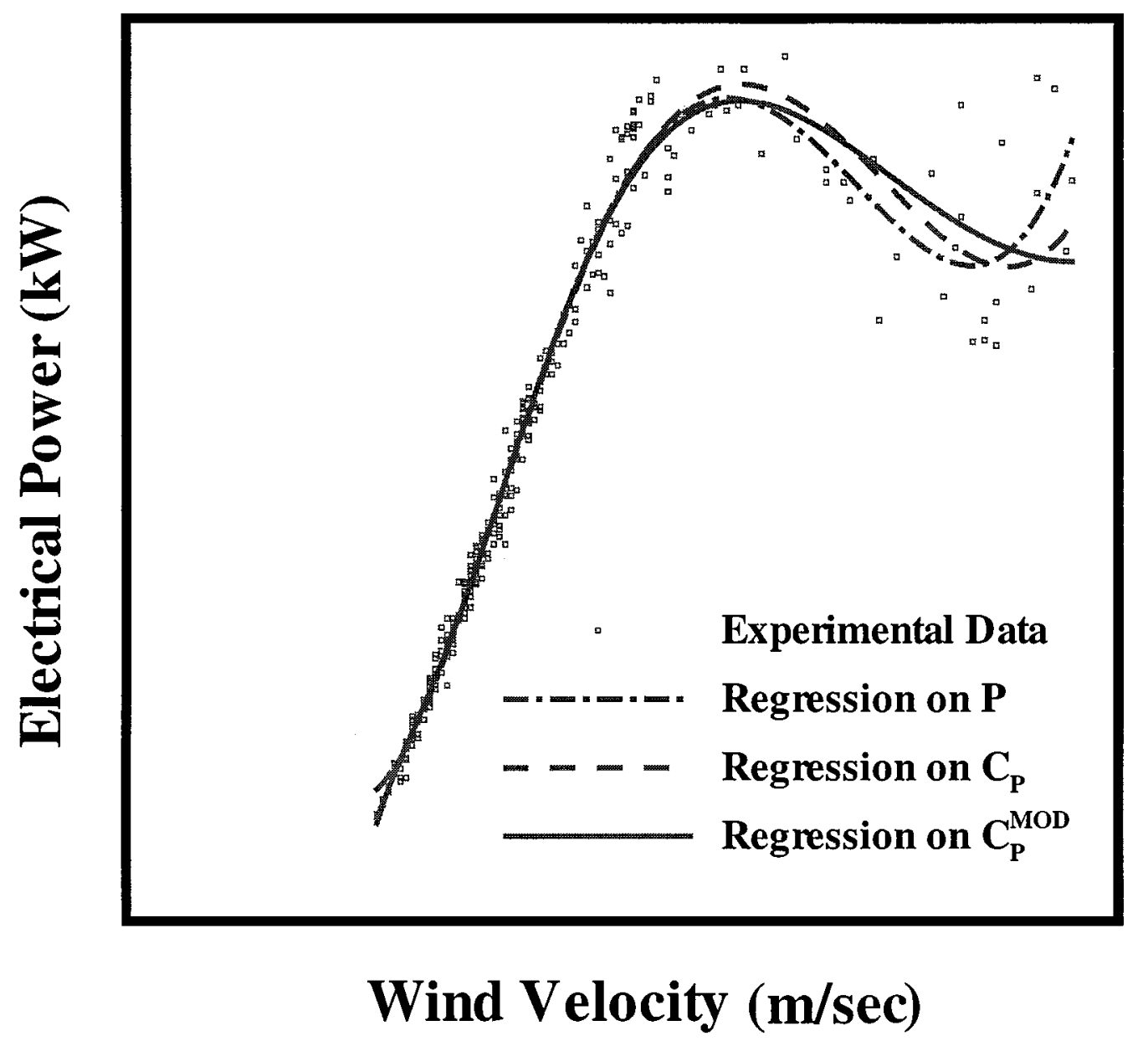

FIGURE 1

Regression analysis for $\omega=27 \mathrm{rpm}$ and $T_{\text {air }}=-5^{\circ} \mathrm{C}$.

obtained from a modified coefficient of power:

$$
C_{P}^{M O D}=\frac{P}{\frac{1}{2} \rho\left(V_{\text {STALL }}\left(1-e^{-\frac{V}{V_{\text {STALL }}}}\right)\right)^{3} \pi R^{2}}
$$

where $V_{S T A L L}$ is the stall velocity of the turbine, defined as the wind velocity for which power output is maximum. This redefinition of the coefficient of power has been proposed so as to limit its asymptotic behavior at high wind velocities. Other variable changes may also be used to obtain a regression function of the form $a V^{3}+b V^{2}+c V+d+e / V+f / V^{2}+g / V^{3}$, or of higher order, but no significant improvement has been found with these higher order approaches, as the curves found resemble those derived by using classical polynomial regression.

\section{Uncertainties Related to Evaluation of the Power Curves}

In the near-stall and post-stall regions of operation, power values are subject to significant scatter because small changes in the turbine's operational parameters strongly influence the rotor's aerodynamics (see Figures 1 and 2). When only a few recordings are available in these regions, regression of the experimental data becomes questionable. Errors might also come from the sensors used to measure wind velocity, temperature, power, and other parameters of interest, as their behavior might be influenced by wear resulting from long use, dirt, or ice accretion. Furthermore, two recordings having identical temperature and 10-min-averaged wind velocity at hub height can have differing atmospheric pressure, air relative humidity, and vertical and time distribution of wind. Wind turbine standards generally neglect these parameters in the evaluation of power curves. However, Elliott and colleagues (1990) showed, for example, that atmospheric turbulence has an important effect on power.

The goal of the proposed regression method was to find the best estimates of the power curves for each integer value of the air temperature in the range of interest. The true power curves of the turbine were defined as those estimated from an infinite number of recordings distributed within the full range of operation of the turbine, so it was necessary first to evaluate discrepancies between the best estimates and the true curves in order to assess the validity of the subsequent analysis. Quantification of the uncertainties related to the proposed regression method required 


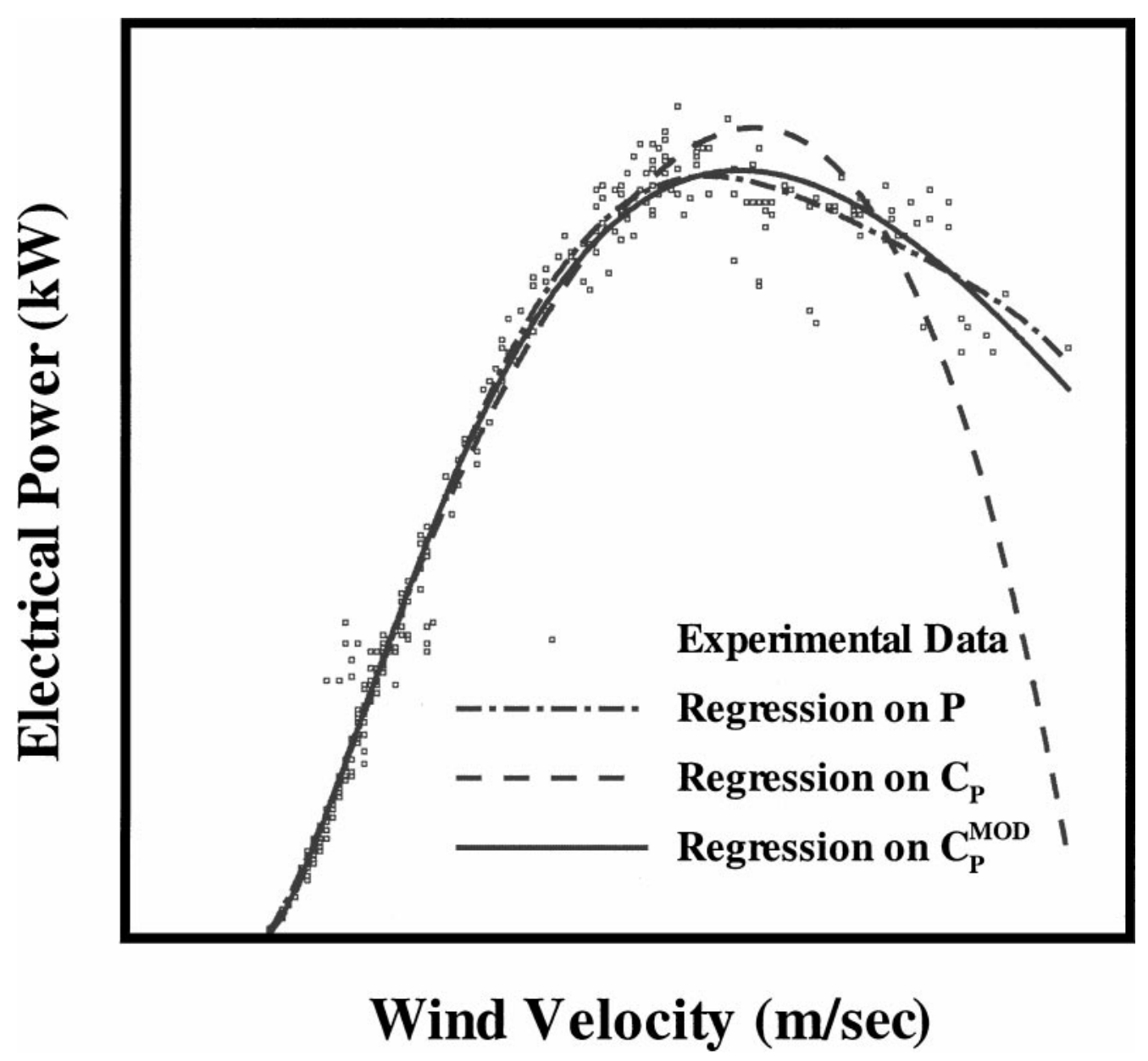

FIGURE 2

Regression analysis for $\omega=18 \mathrm{rpm}$ and $T_{\text {air }}=-8^{\circ} \mathrm{C}$.

an extensive study of the aforementioned sources of errors. In the following sections, it was assumed that the power curves obtained using the proposed regression method were the best estimates of the true power curves that could be obtained from the available experimental data. This assertion is especially true for wind velocities between 4 and $9 \mathrm{~m} / \mathrm{sec}$, as numerous data have been recorded in this range.

\section{EFFECT OF TEMPERATURE ON POWER OUTPUT}

As with electrical power, for a given rotational speed, the effect of temperature on power output was assumed to be a function of wind velocity and temperature. Taking the $15^{\circ} \mathrm{C}$ power curve as a reference, we defined the relative increase in power by using the following ratio:

$$
\Delta_{P}(V, T)=\frac{P(V, T)}{P\left(V, 15^{\circ} \mathrm{C}\right)}
$$

where $P(V, T)$ is the power obtained from the regression on $C_{P}^{M O D}$ and $P\left(V, 15^{\circ} \mathrm{C}\right)$ is the electrical power obtained from the regression on $C_{P}^{M O D}$ at the same wind velocity, but for a standard temperature of $15^{\circ} \mathrm{C}$. It is important to note that there are two $\Delta_{P}$ functions corresponding to the two modes of operation of the turbine. The domain of existence of a given $\Delta_{P}$ function is imposed by experimental recordings. For example, in the case of the high rotational speed mode of operation, wind velocities observed at $-40^{\circ} \mathrm{C}$ ranged between $4.5 \mathrm{~m} / \mathrm{sec}$ and $6.5 \mathrm{~m} / \mathrm{sec}$, whereas those at $-5^{\circ} \mathrm{C}$ ranged between $4 \mathrm{~m} / \mathrm{sec}$ and $16 \mathrm{~m} / \mathrm{sec}$. In addition, no recordings were available for temperatures between $-39^{\circ} \mathrm{C}$ and $-24^{\circ} \mathrm{C}$ (for both modes of operation of the turbine), so the study of the effect of very cold temperatures on the turbine performances was limited. Figure 3 shows, for the high rotational velocity of the turbine, constant-velocity contour plots of the $\Delta_{P}$ function as a function of temperature for wind velocities of 5, 8 , and $11 \mathrm{~m} / \mathrm{sec}$. Values of the $\Delta_{P}$ function are represented by symbols, as they show some scattering. Nevertheless, the 5 and $8 \mathrm{~m} / \mathrm{sec}$ constant-velocity contour plots clearly exhibit a linear tendency. This linear behavior is less evident for the $11 \mathrm{~m} / \mathrm{sec}$ constant-velocity contour, and this might be attributed to the very small amount of experimental data available for this wind velocity. The analysis of all contour plots of the $\Delta_{P}$ functions for both rotational speeds of the turbine's operation clearly indicated 


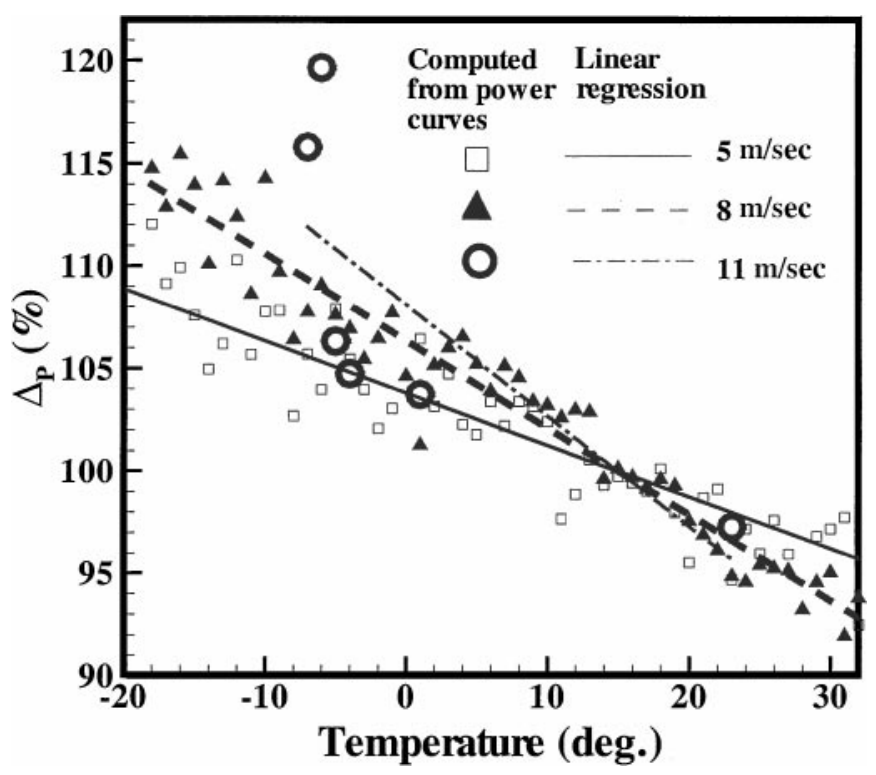

FIGURE 3

Five $\mathrm{m} / \mathrm{sec}, 8 \mathrm{~m} / \mathrm{sec}$, and $11 \mathrm{~m} / \mathrm{sec}$ constant-velocity contours of $\Delta_{P}$ for $\omega=27 \mathrm{rpm}$.

linear behavior in the velocity range of $4 \mathrm{~m} / \mathrm{sec}$ to $9 \mathrm{~m} / \mathrm{sec}$, but no clear tendency was observed for higher velocities.

Because the power performance curve obtained from the regression on $\mathrm{C}_{P}^{M O D}$ for the standard temperature, $P\left(V, 15^{\circ} \mathrm{C}\right)$, does not effectively cover the whole range of wind velocities recorded; another procedure had to be used to get the value of $P\left(V, 15^{\circ} \mathrm{C}\right)$. In this work, for a given wind velocity, linear regression was applied to the constant-velocity contour lines of the $P(V, T)$ function, and the value of the electrical power at $15^{\circ} \mathrm{C}$ was obtained from the derived linear expression. Calling $P_{R E F}\left(V, 15^{\circ} \mathrm{C}\right)$ the value of this electrical power of reference, the relative increase in power was redefined, for the purpose of consistency, as

$$
\Delta_{P}(V, T)=\frac{P(V, T)}{P_{R E F}\left(V, 15^{\circ} \mathrm{C}\right)}
$$

Figure 4 shows results similar to those presented in Figure 3, but for wind velocities of 7 and $12 \mathrm{~m} / \mathrm{sec}$. At $12 \mathrm{~m} / \mathrm{sec}$, relative power increases are surprisingly high. Five points plotted as wind velocities higher than $12 \mathrm{~m} / \mathrm{sec}$ were recorded for five different temperatures only. Considering the relatively small number of experimental recordings used to obtain regression curves at such high velocities, definitive conclusions about the systematic behavior of power increases in this range of velocity can hardly be formulated.

Figures 5 and 6 present the values of the relative increases in power for the low and high rotational speeds, respectively, for all wind velocities. With these figures, the relative increase in air density is also presented, as it represents the theoretical power increase of a rotor immersed in a uniform and inviscid incoming flow. The curve describing the relative increase in air density

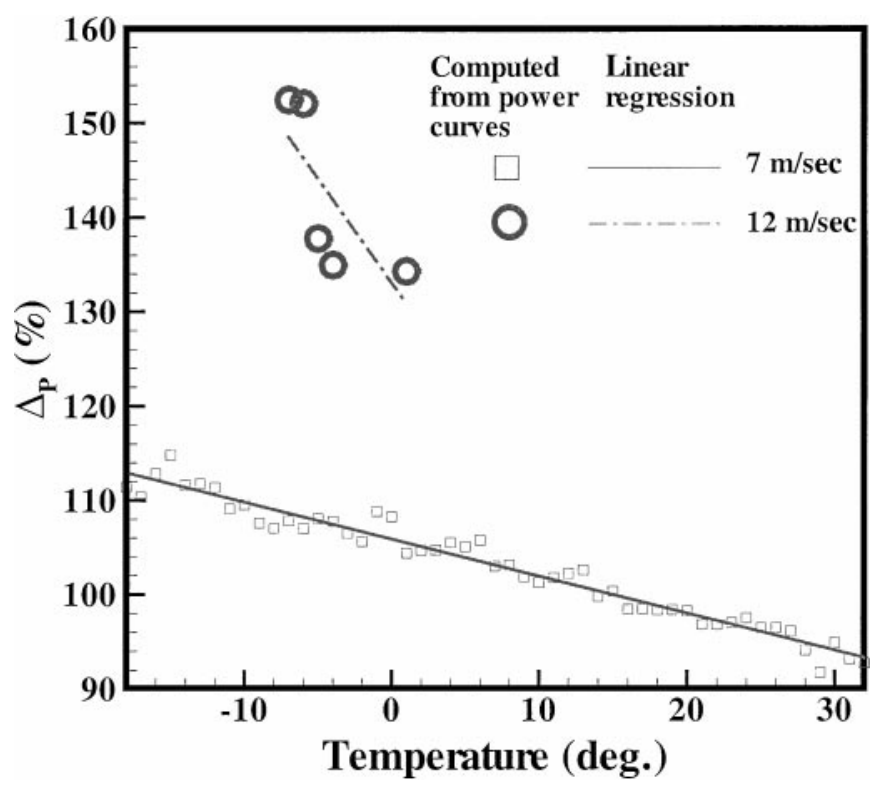

FIGURE 4

Seven $\mathrm{m} / \mathrm{sec}$ and $12 \mathrm{~m} / \mathrm{sec}$ constant-velocity contours of $\Delta_{P}$ for $\varphi=27 \mathrm{rpm}$.

is obtained through a polynomial regression analysis of the air density computed for all available recordings. (The derivation of this curve and its interpretation are described in the next section). The two figures indicate that increases in power generally follow the same trend as the increase in air density. For the low rotational mode, however, increases in power measured in cold weather were generally higher than increases in air density, and for both modes of operation, a large number of values representing the increase in power are found to exceed the variations in air density.

Figures 7 and 8 show the linear estimates of the relative increase in electrical power for the low and high rotational speeds of the turbine, respectively, when stratified by wind velocities. The relative increase in air density is also plotted on these figures. For clarity of presentation, all wind velocities are not shown on the drawings. At the low rotational speed, the contour line plots obtained for $3 \mathrm{~m} / \mathrm{sec}, 4 \mathrm{~m} / \mathrm{sec}$, and $5 \mathrm{~m} / \mathrm{sec}$ are nearly identi$\mathrm{cal}$, as are those obtained for $7 \mathrm{~m} / \mathrm{sec}, 9 \mathrm{~m} / \mathrm{sec}$, and $10 \mathrm{~m} / \mathrm{sec}$, and those obtained for 6 and $12 \mathrm{~m} / \mathrm{sec}$. At the high rotational speed, contour line plots that coincide are those for $7 \mathrm{~m} / \mathrm{sec}$ and $9 \mathrm{~m} / \mathrm{sec}$, whereas the $8 \mathrm{~m} / \mathrm{sec}$ contour line plot is very close to the curve for relative air density variations. For a given temperature, it clearly appears that $\Delta_{P}$ increases with the wind velocity, the maximum being reached for wind velocities corresponding to stall operation of the turbine (between $9 \mathrm{~m} / \mathrm{sec}$ and $12 \mathrm{~m} / \mathrm{sec}$ ). Moreover, for these high wind velocities, the relative increase in power output generally exceeds the variations in air density, the contour line plot for the low rotational mode at $12 \mathrm{~m} / \mathrm{sec}$ being the only exception. Extrapolation of these tendencies at lower temperatures indicated that temperature may have a substantial effect on power output that is not explained solely by the air density variations. 


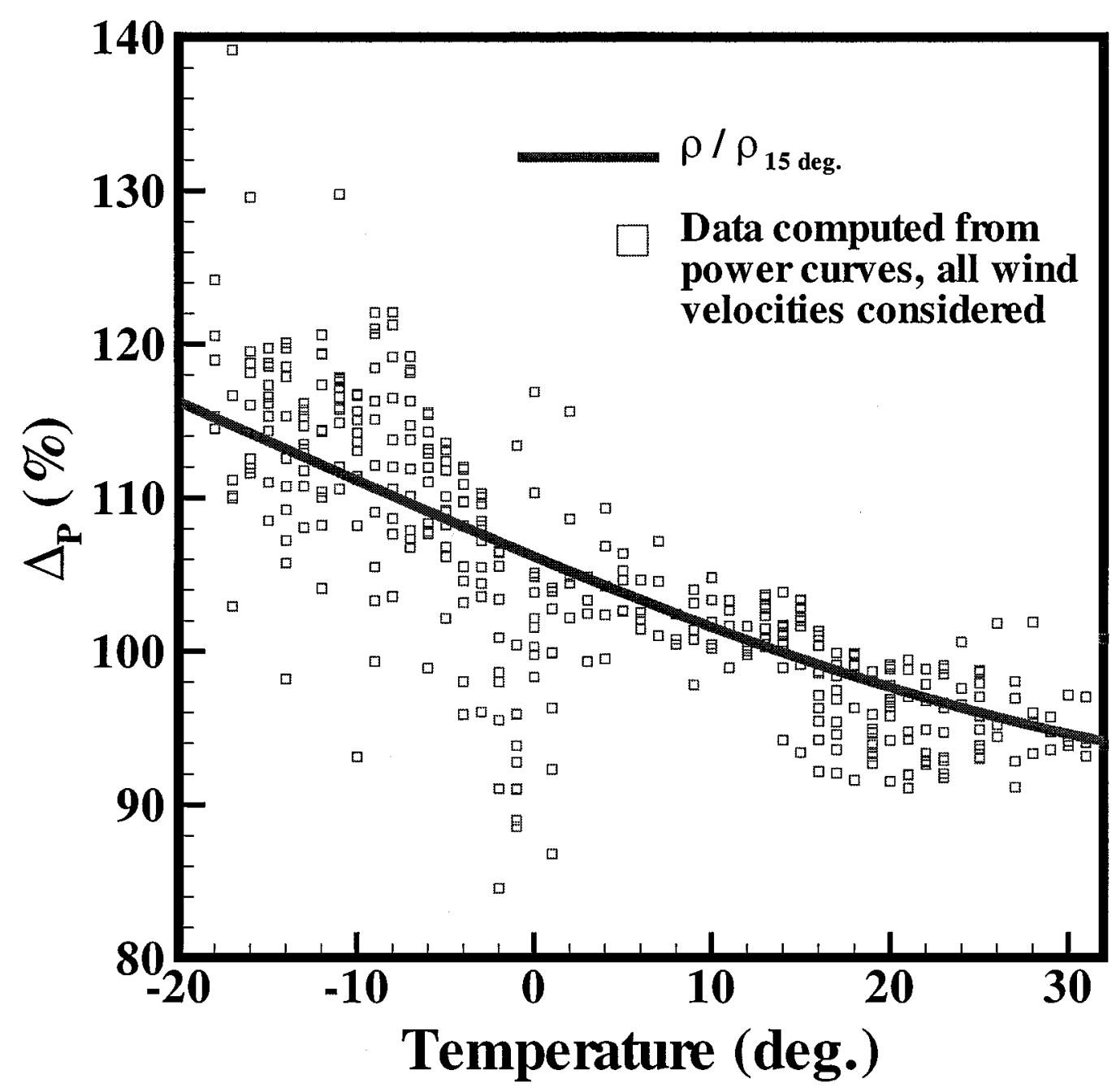

FIGURE 5

Temperature effect on power output for $\omega=18 \mathrm{rpm}$ (all wind velocities considered).

In summary, the effect of temperature on power output can be expressed by the linear expression

$$
P(V, T)=P\left(V, T_{R E F}\right)^{*}\left(1+\alpha(V)\left(1-\frac{T}{T_{R E F}}\right)\right)
$$

where $T_{R E F}$ is a reference temperature and $\alpha$ is a nondimensional number, a function of the wind velocity, whose value is obtained by applying linear regression to the constant-velocity contour plots of the $\Delta_{P}$ function. Considering the air a perfect gas, and assuming that increases in power output are directly proportional to density variations, it can be proven that $\alpha$ is very close to 1 . Table 1 gives the value of $\alpha$, computed from the present data, for the two rotational speeds of the turbine $\left(T_{R E F}=15^{\circ} \mathrm{C}\right)$.

It is important to note that the wind velocities were those measured by the turbine's anemometer, which is located on the top of the nacelle, downwind from the blades. Therefore, the values of wind velocity are affected by the rotor's operation and are substantially lower than the velocity of the incoming wind.
Finally, it was found that for both of the rotational modes of the turbine, the wind velocity for which the rotor operated at its maximum efficiency (i.e., $C_{P}$ is a maximum) was independent of temperature. This finding is of major importance to the operation of variable-speed wind turbines, as it means that the optimization algorithm for these turbines can be designed without consideration of the effects of temperature.

\section{STUDY OF VARIATIONS IN AIR DENSITY AND REYNOLDS NUMBER}

It was postulated earlier that the power output could be expressed as a function of wind velocity and temperature only. Another parameter of interest is the wind's direction. However, study of this parameter indicated that wind direction may be considered to have a negligible effect on the power output of the Tiverton rotor. To evaluate the possible effects of temperature on air density and Reynolds number, examination of the correlation existing between these parameters and the air temperature was performed. 


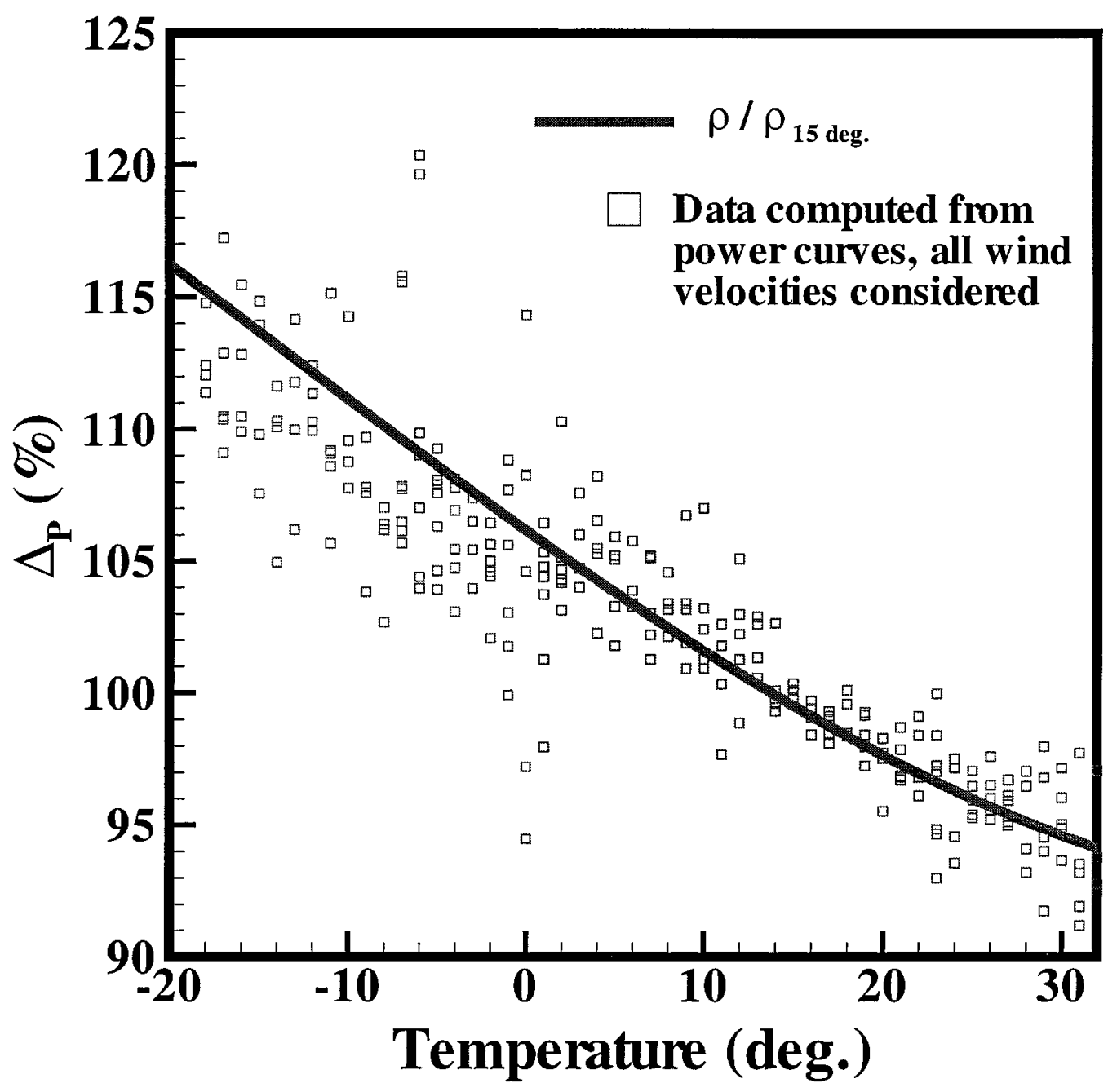

FIGURE 6

Temperature effect on power output for $\omega=27 \mathrm{rpm}$ (all wind velocities considered).

\section{Variations in Air Density}

Air density $(\rho)$ acts as a proportional factor in the fluid momentum balance through the turbine and therefore has a proportional influence on the rotor's mechanical power. Air density is a function of temperature, atmospheric pressure, and humidity. The last two air properties have been provided by Environment Canada for the nearby site of Goderich. Figure 9 is a plot of all air density values as a function of temperature for all recordings of the two modes of the turbine's operation. This figure shows that there is a strong correlation between air density and temperature; therefore, temperature variations imply well-defined air density variations.

\section{Variations in the Reynolds Number}

Variations in the Reynolds number change the structure of the flow by modifying the relative effect of viscous forces when compared to inertia forces. These variations are susceptible to modifying the aerodynamic performances of the blade and, thus, the mechanical power. In the expression of the Reynolds number, characteristic length and velocity appeared, but these parameters are not functions of temperature. Because we were interested in temperature-dependence only, we were interested in the unit's Reynolds number, which is defined as

$$
\operatorname{Re}=\frac{\rho}{\mu}
$$

Figure 10 shows that a well-defined relationship can be established between temperature and the unit's Reynolds number. For the two-dimensional problem of air flowing around a fixed aerodynamic profile, lift and drag are strongly dependent on the Reynolds number. Therefore, the Reynolds number was expected to have a strong influence on the mechanical power of the wind turbine. 


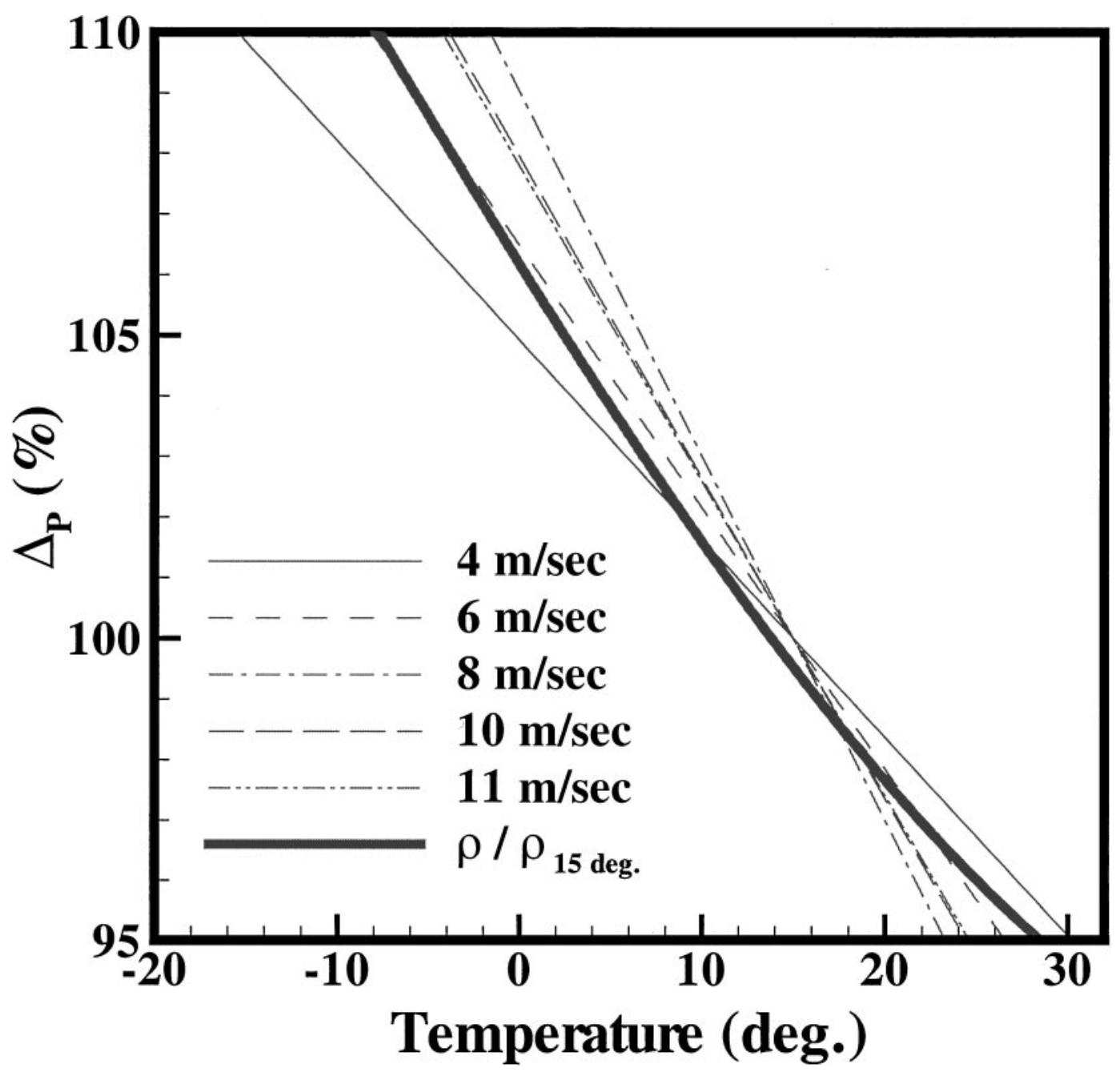

FIGURE 7

Linear estimation of the relative power increase as a function of temperature, stratified by wind velocities for $\omega=18 \mathrm{rpm}$.

\section{THE EFFECTS OF TEMPERATURE ON OTHER PARAMETERS}

Temperature variations may influence the following parameters which, in turn, affect the electrical power output of a wind turbine:

- The vertical distribution of wind velocity and turbulence intensity. These parameters are strongly dependent on the effects of ground and sun radiation. The deposit of snow or ice changes the ground shear stress, and colder climates influence the effects of the sun's radiation and the thermodynamic properties of the ground.

- Large time-scale structures of the flow. Such structures are responsible for temporal wind-velocity variations, which may have an influence on 10-min-averaged values of power.
- The position along each blade of the laminar-toturbulent transition of the flow. The transition phenomenon is highly dependent on the Reynolds number and is seriously influenced by disturbances in the incoming flow. Laminar-to-turbulent transition strongly influences the structure of the flow around the blades.

- The general efficiency of the rotor in converting mechanical power into electrical power.

\section{EVENTS OF MULTIPLE STALL}

In the analysis of the experimental data, two apparent events of multiple stall were identified. Multiple stall is observed on power curves determined experimentally and is defined as the occurrence of distinct power bands, generally at high wind velocities. A turbine is subject to operating at different power levels for a given wind velocity. 


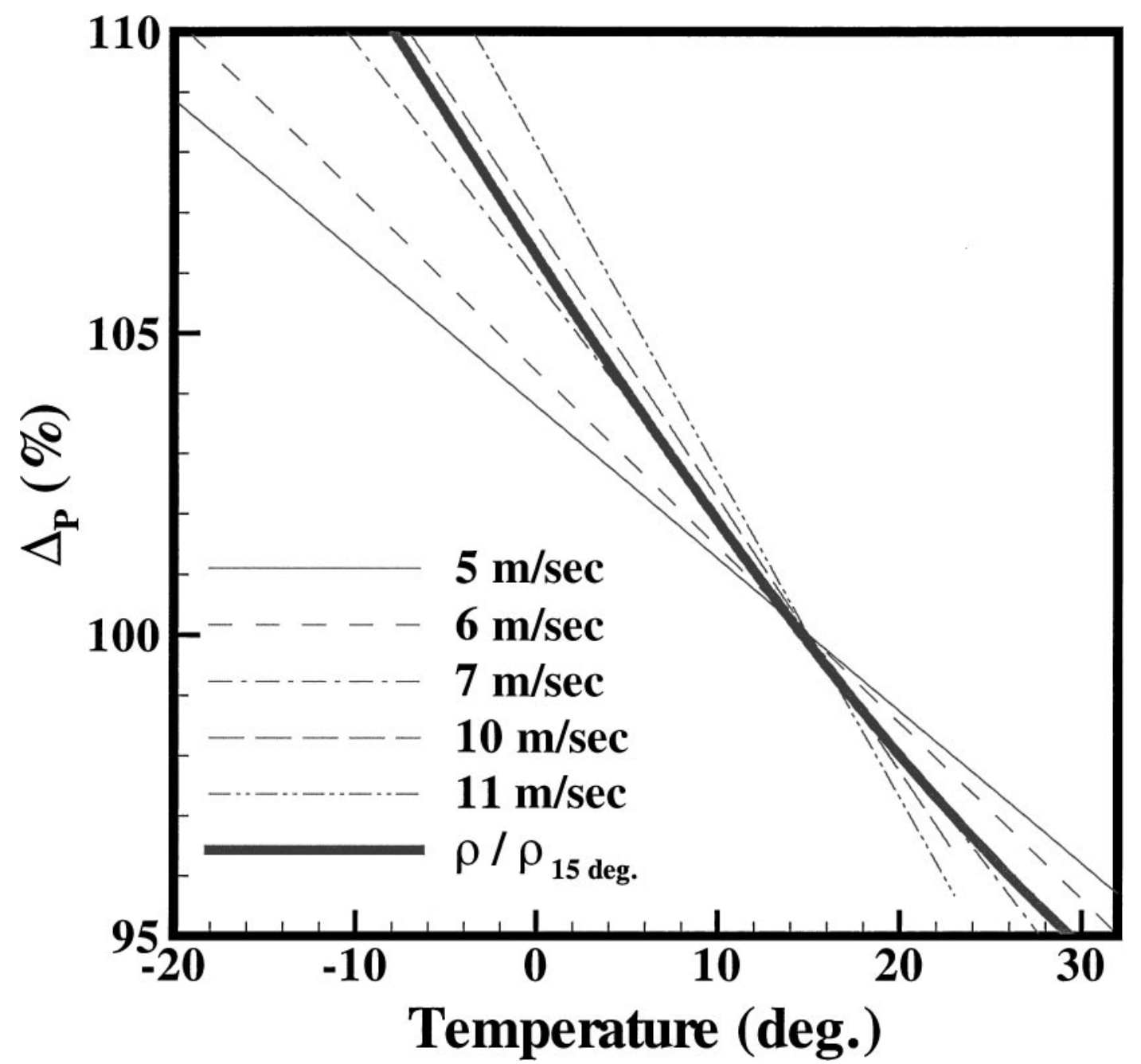

FIGURE 8

Linear estimation of the relative power increase as a function of temperature, stratified by wind velocities for $\omega=27 \mathrm{rpm}$.

Figures 11 and 12 show the power curves of $0^{\circ} \mathrm{C}$ recordings in the high-rotation mode of the turbine and of $-9^{\circ} \mathrm{C}$ recordings in the low-rotation mode. Two levels of stall are clearly visible, the higher one occurring with a stronger probability. Both multiple stall phenomena cause a decrease in power output and may therefore not be responsible for any high-power excursion. A statistical study of the influence of air density, Reynolds number, and wind direction indicated that multiple stall phenomena are independent of those parameters.

\section{TABLE 1}

Effects of Temperature on Power Output

\begin{tabular}{cccccccc}
\hline $\begin{array}{c}\text { Wind velocity } \\
(\mathrm{m} / \mathrm{sec})\end{array}$ & 5 & 6 & 7 & 8 & 9 & 10 & 11 \\
\hline$\omega=18 \mathrm{rpm}$ & 0.98 & 1.25 & 1.54 & 1.73 & 1.52 & 1.53 & 1.50 \\
$\omega=27 \mathrm{rpm}$ & 0.73 & 0.84 & 1.13 & 1.22 & 1.11 & 1.30 & 1.56 \\
\hline
\end{tabular}

\section{CONCLUSION}

Four stall-controlled wind turbines operating in very cold weather produced higher than predicted power outputs, which led in some cases to dramatic failures of their electrical conversion systems. Many occurrences of this phenomenon were monitored, so a systematic study of air temperature effects must be undertaken in order to clarify whether or not temperature plays a significant role in power production by a turbine.

In this article, the Tacke TW600 located near Tiverton, Ontario, was studied because similar problems were encountered in the beginning of its operation in November 1995. For this analysis, 22,000 recordings of 10-min-averaged values of power, wind velocity, air temperature, and wind direction, describing more than 2 years of operation, were used. For both the low- and high-rotational modes of the turbine, and for each integer value of the temperature between $-24^{\circ} \mathrm{C}$ and $36^{\circ} \mathrm{C}$, regression analysis was performed on the recordings to determine the power curves of the turbine. Then the effects of temperature 


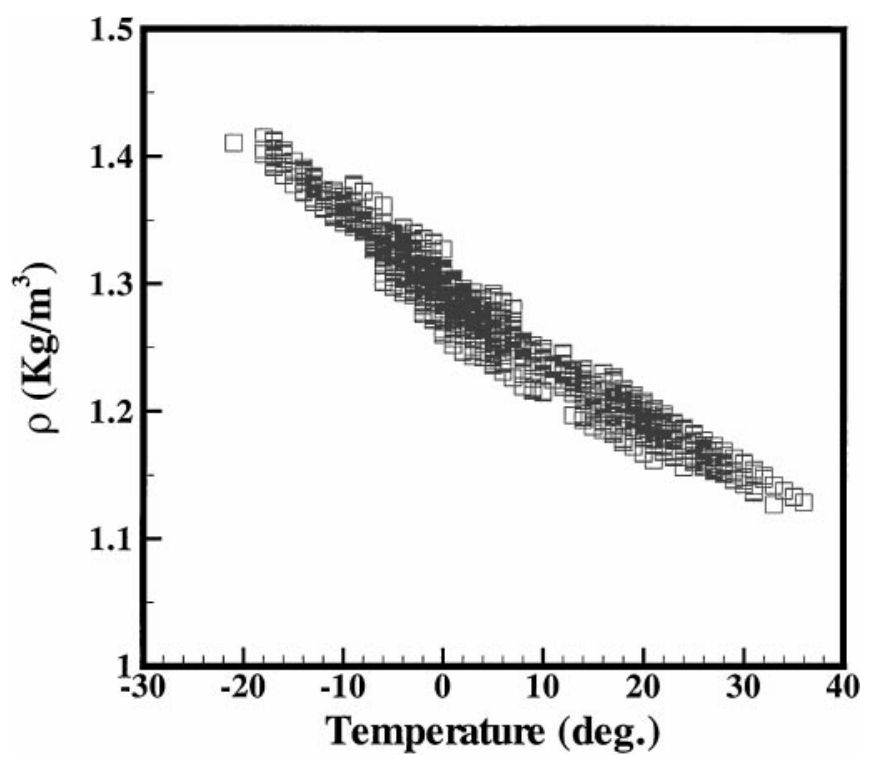

FIGURE 9

Air density as a function of temperature.

were analyzed by studying the relative power increases as a function of temperature for a given wind velocity. The values of power used were those obtained from the regression analysis. With some exceptions, it was observed that the effects of temperature on the relative power output for a given wind velocity is well-represented by a linear regression. When all linear curves describing temperature effects on power augmentation were stratified by wind velocities, it clearly appeared that relative power increases are more important at high wind velocities. Comparison of these increases with the theoretical limit imposed by air-density fluctuations showed that power variations

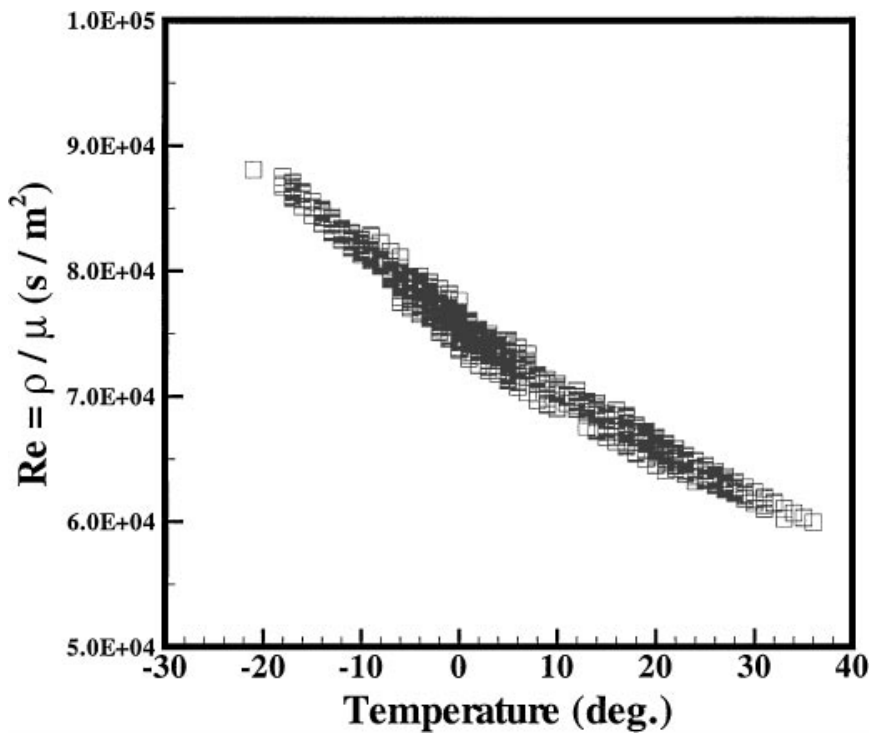

FIGURE 10

Unit Reynolds number as a function of temperature.

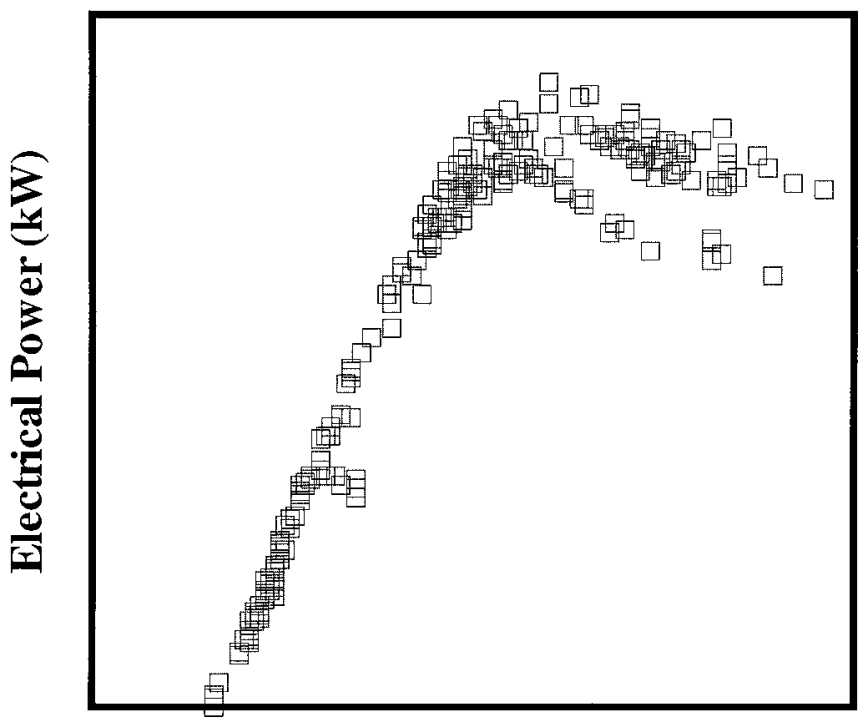

\section{Wind Velocity $(\mathrm{m} / \mathrm{sec})$}

FIGURE 11

Evidence of double stall for $\omega=18 \mathrm{rpm}$ and $T_{\text {air }}=-9^{\circ} \mathrm{C}$.

are comparable and are even higher than variations in air density. However, these findings should be considered preliminary conclusions; it was not possible to assess the uncertainties associated with data acquisition, and the lack of experimental data in some operational ranges of the turbine might have influenced some of the trends observed.

Study of the correlation among air density, the unit's Reynolds number, and temperature indicated that well-defined relationships exist among these values. In the case of a rotor immersed

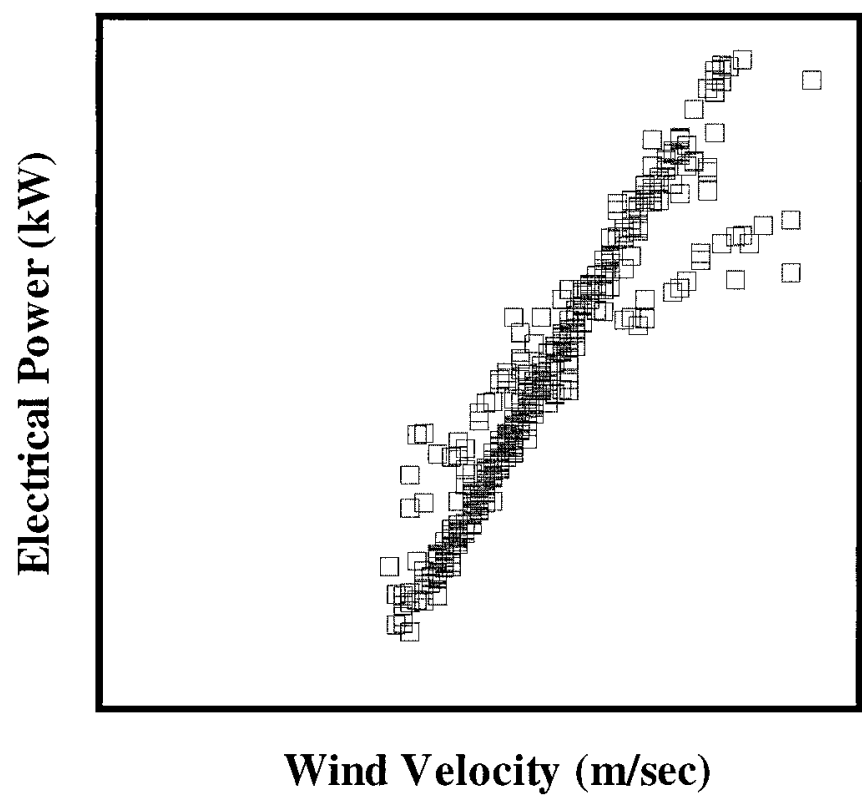

FIGURE 12

Evidence of double stall for $\omega=27 \mathrm{rpm}$ and $T_{\text {air }}=0^{\circ} \mathrm{C}$. 
in a uniform and inviscid incoming flow, air density is expected to act as a proportional factor in the power output's dependence on air temperature. Reynolds number variations strongly influence the aerodynamics of the blade. Other parameters that are dependent on air temperature and that influence power production are the vertical distribution of the velocity and the turbulence characteristics of the incoming flow; the position of the laminarto-turbulent transition along the blade surfaces, and the general efficiency of the electrical conversion system.

On a statistical basis, abnormally high power excursions were not exhibited by this analysis; lack of data concerning performance below $-24^{\circ} \mathrm{C}$ excluded analysis at very low temperatures. Nevertheless, extrapolation of the study's results indicates that power variations might greatly exceed air-density variations. Analysis of additional experimental data is therefore necessary to confirm and broaden the conclusions of this study. A detailed measurement program is also necessary so as to control the precision of the input parameters and achieve a bet- ter understanding of all the mechanisms that influence power production.

\section{REFERENCES}

Elliott, D. L., and Cadogan, J. B. 1990. Effects of wind shear and turbulence on wind turbine power curves. Proceedings of the European Community Wind Energy Conference and Exhibition. Madrid, Spain, Sept. 10-14, pp. 79-83.

Lodge, M. A. 1996. Operational experience with and performance of two $10 \mathrm{~kW}$ aerowatt wind turbines at Igloolik, NWT, Canada. Proceedings of the BOREAS III Wind Conference. Saariselkä, Finland, March 19-21, pp. 75-93.

Peltola, E., Marjaniemi, M., Kaas, J., and Aarnio, E. 1996. Pyhätunturi operational experiences. Proceedings of the BOREAS III Wind Conference. Saariselkä, Finland, March 19-21, pp. 131144.

Reid, R. 1998. Personal communication. Institut de Recherche en Électricité du Québec (IREQ), Varennes, Canada. 

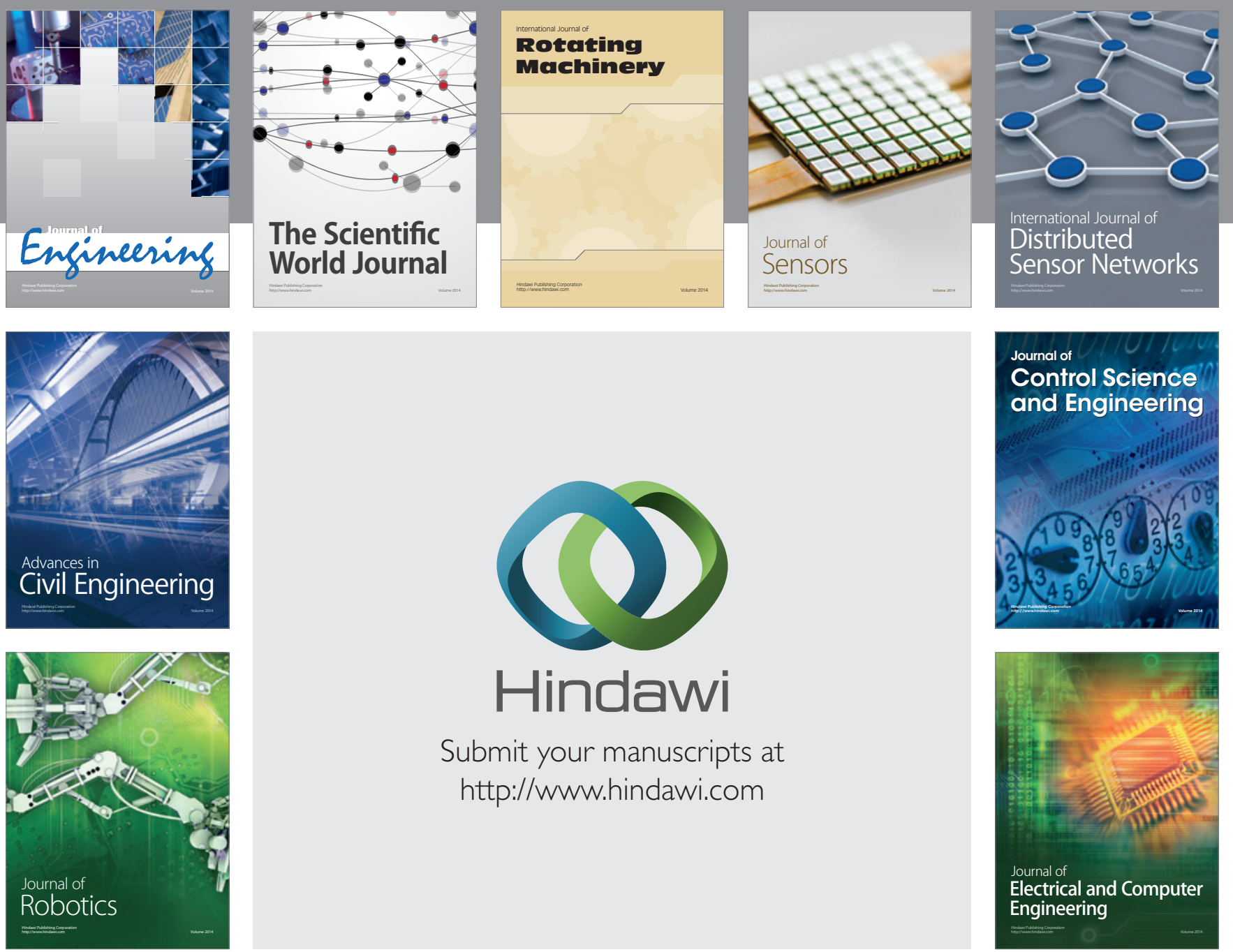

Submit your manuscripts at

http://www.hindawi.com
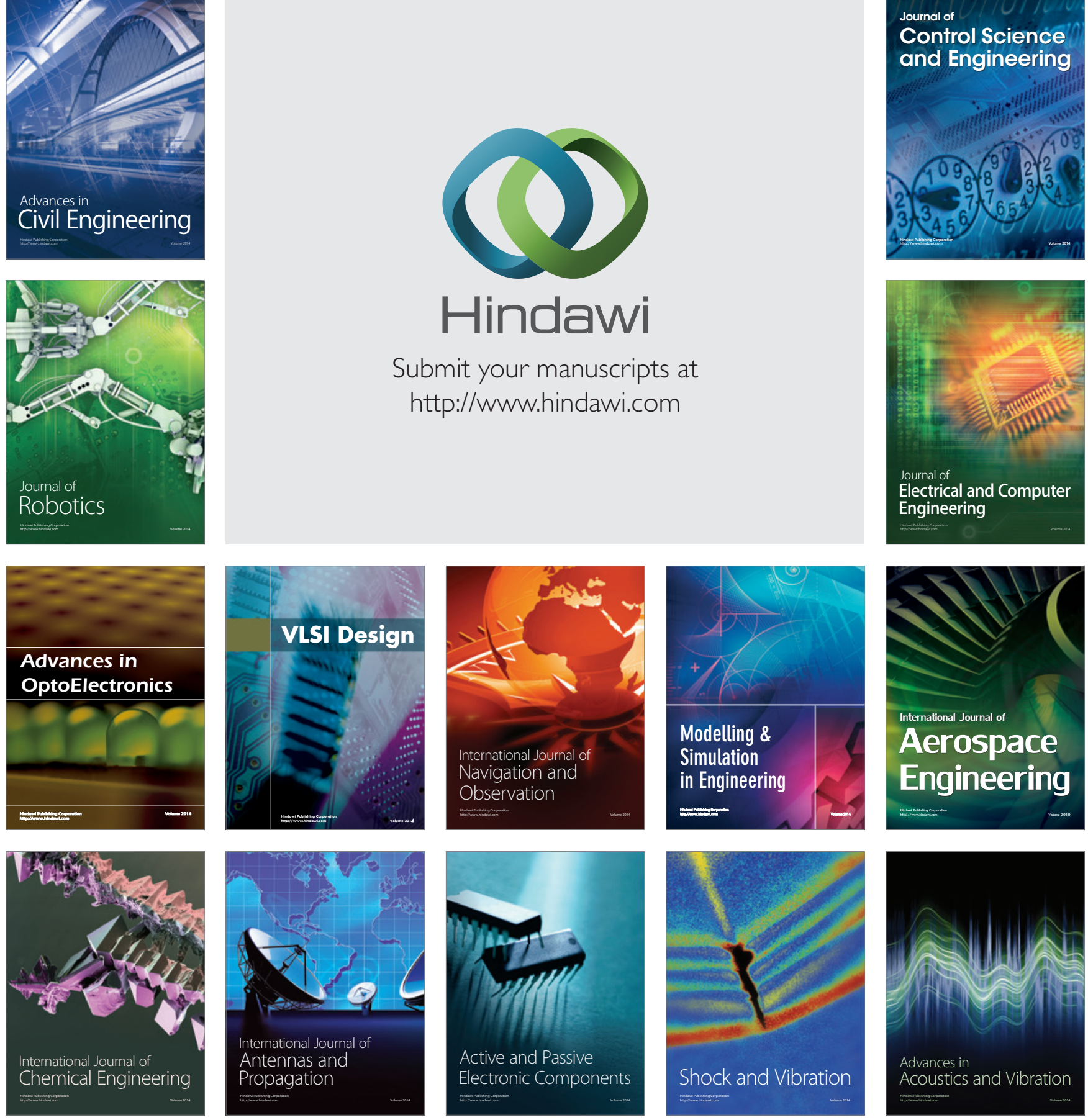